Egyptian

Orthodontic Journal

\title{
DENTO-SKELETAL CHANGES ASSOCIATED WITH TREATMENT OF DEEP OVERBITE IN CLASS II MALOCCLUSION
}

\author{
Safaa Ali Ghobashy ${ }^{1}$
}

\section{ABSTRACT:}

The present study aimed to evaluate the treatment changes in class II patients with deep overbite. A total of 22 females (15-18 years) were treated with fixed orthodontic appliances divided into 2 groups; the first group comprised of 12 cases with class II division 1and the second group ten cases with class II division 2. All cases possessed over bite more than $4 \mathrm{~mm}$, class II more than 4 degrees and had pre and post treatment lateral cephalometric $x$-ray films. Eleven angular and ten linear cephalometric measurements were recorded and analyzed before and after treatment. The differences in mean values of variables within each studied group were statistically analyzed using Wilcox on singed rank test. On the other hand the mean differences of overbite before and after intervention were compared between the two studied groups using Mann-Whitney test.

Results: Bite depth improved an average of $5.6 \mathrm{~mm}$ in class $I I$ division1, and $2.6 \mathrm{~mm}$ in class II division2 with significant differences within and between the studied groups. All measurements showed changes that were statistically significant except $S \mathcal{N} B^{0}$ in 6oth groups, $\mathcal{A N} B^{0}, O P / \mathcal{M} P^{0}, V 1-P P, A \mathcal{N S}-\mathcal{M e}$ in group 1, and $\mathcal{L} 1-\mathcal{M} P$ in group 2.

Conclusion: Bite depth improved due to the changes in the axial inclination of incisor teeth that were decreased in class II division1, while increased in class II division 2, intrusion of lower

1- Associate Professor of Orthodontic Department, Faculty of dentistry, Tanta University. 
Egyptian

Orthodontic Journal

incisor in class II division1, and intrusion of maxillary incisor in class II division 2 in addition to extrusion of upper and lower molars in both groups.

\section{INTRODUCTION}

An increased overbite (deep bite) is one of the most common malocclusions and the most difficult to treat successfully. It is not considered usually as a specific malocclusion, and it is an attribute of other discrepancies in the sagittal plane, with special regard to class II division 1 and division 2 malocclusions ${ }^{1,2}$.

Through the years, opinions have differed regarding the etiology of deepbite and how they should be treated. It has been related to a lack of vertical growth in the molar and premolar regions, and / or supra eruption of incisors and canines, excessive overjet, and incisor angulation ${ }^{3-5}$. Facial type and lower facial height are thought to play a major role in predicting how an individual will response to treatment ${ }^{6,7}$.

For optimal results, the need for careful diagnosis and a logically sequenced plan of treatment is critical. Treatment approaches include transition from a horizontal to a vertical growth pattern by forcing the mandible into a clockwise rotation, intrusion of anterior teeth, or extrusion of posterior teeth, or a combination of both, and surgical approaches ${ }^{7,8}$. Unfavorable consequences of an untreated "deep bite include an increase in anterior crowding, maxillary dental flaring, and associated periodontal sequelae ${ }^{9}$.

Several mechanics have been described for the correction of deep overbite. Tip-back bends and base arches are some of the mechanics that have been suggested for the extrusion of posterior teeth ${ }^{10-13}$. In order to intrude the incisors, J-hook headgears, functional appliances, anterior bite-planes, segmented arch technique, Begg mechanics, edgewise mechanics, three piece base arch, utility intrusion arch, connecticut intrusion arch, and temporary anchorage device can be used ${ }^{14-22}$. The specific treatment objectives need to be determined before the mechanotherapy is initiated. To reduce unwanted movements of teeth during treatment, it must be decided which area is the cause of the 
Egyptian

Orthodontic Journal

deep bite, and prescribe the mechanics to correct the problem. Evaluations of post treatment results may reveal how well these objectives achieved.

The purpose of the present study was to evaluate the treatment outcomes of class II division 1 and class II division 2 malocclusions with deep bites that have been treated with fixed appliance.

\section{MATERIALS AND METHODS}

This study examined the cephalometric films of 22 female patients (15-18 years old) treated in Orthodontic Department, Faculty of Dentistry, Tanta University and the private clinic. Criteria for selection consisted of the availability of adequate pretreatment and post treatment cephalograms (T 1 and T 2), class II cases with $\mathrm{ANB}^{0}$ more than $4^{0}$, deep overbite $>4 \mathrm{~mm}$. There were 12 patients with class II division 1 treated with an extraction protocol, and 10 patients with class II division 2 treated without extraction.

The patients underwent the treatment with fixed appliances (0.022-inch slot, edgewise brackets). The duration of treatment with fixed appliances was 23 months on average. The radiographs, T1- T2, were traced to allow identification of points, lines and planes. The cephalograms were analyzed and re-evaluated after 2 weeks. If the limits between the 2 readings exceeded $0.5 \mathrm{~mm}$ and $0.5^{\circ}$, a third measurement was made, and an average of the nearest two measurements was taken. Eleven angular and ten linear measurements (Fig.1,2) were performed as follow:

- SNA $\left({ }^{\circ}\right)$ : The angle formed by the planes Sella-Nasion and Nasion-Point A.

- SNB $\left({ }^{\circ}\right)$ : The angle formed by the planes Sella-Nasion and Nasion-Point B.

- ANB ( ${ }^{\circ}$ ): The angle formed by the planes Nasion-Point A and Nasion-Point B.

- SN/MP $\left({ }^{\circ}\right)$ : The angle formed by Sella-Nasion and Gonion-Gnathion or the mandibular plane.

- SN/OP( $\left(^{\circ}\right)$ : The angle formed between the functional occlusal plane (a line intersecting the intercuspation of the posterior occlusion and the incisor teeth) and Sella-Nasion plane. 
- OP/MP $\left({ }^{\circ}\right)$ : The angle formed between the functional occlusal plane and mandibular plane.

- ANS-Me (mm): Lower anterior facial height.

- S-Go (mm): Posterior facial height.

- $\mathrm{U} 1 / \mathrm{L} 1\left(^{\circ}\right)$ : Interincisal angle; the angle formed by the long axes of the most forward upper and lower central incisors.

- $\mathrm{U} 1 / \mathrm{SN}\left({ }^{\circ}\right)$ : The angle formed by the long axis of the upper incisor and SN plane

- $\mathrm{U} 1 / \mathrm{NA}\left({ }^{\circ}\right)$ : The angle formed by the long axis of the upper incisor and Nasion- A Point.

- U1-NA(mm): The distance from the tip of the upper incisor to a plane from Nasion to Point A.

- $\mathrm{L} 1 / \mathrm{NB}\left({ }^{\circ}\right)$ : The angle formed by the long axis of the lower incisor and a plane from Nasion -to B Point.

- L1-NB(mm): The distance from the tip of the lower incisor to a plane from Nasion to Point B.

- $\mathrm{L} 1 / \mathrm{MP}\left({ }^{\circ}\right)$ : The angle formed by the long axis of the lower incisor and the mandibular plane.

- U1-PP(mm): Perpendicular distance from the tip of the upper incisor to the palatal plane.

- U6-PP(mm): Perpendicular distance from the highest cusp tip of the mesial cusp of mandibular permanent first molar perpendicular to the palatal plane.

- L1-MP(mm): The tip of the most extruded mandibular incisor perpendicular to mandibular plane.

- L6-MP(mm): The highest cusp tip of the mesial cusp of mandibular permanent first molar perpendicular to mandibular plane. 
- Overjet(mm): Measured from the tip of the lower incisor to the tip of the upper incisor along the occlusal plane.

- Overbite(mm): Measured from the tips of the upper and lower incisors perpendicular to the occlusal plane.

\section{STATISTICAL ANALYSIS}

The collected data were organized, tabulated and statistically analyzed using SPSS software statistical package version 19. For each variable, the mean and standard deviation were calculated. Non-parametric tests of significance were used as the small sample size can't ensure normal distribution of the studied variables. The differences in mean values of variables within each studied groups was statistically analyzed using Wilcoxon singed rank test. On the other hand the mean differences of overbite before and after intervention were compared between the two studied groups using Mann-Whitney test. The level of significance was adopted at $\mathrm{P}<0.05$.

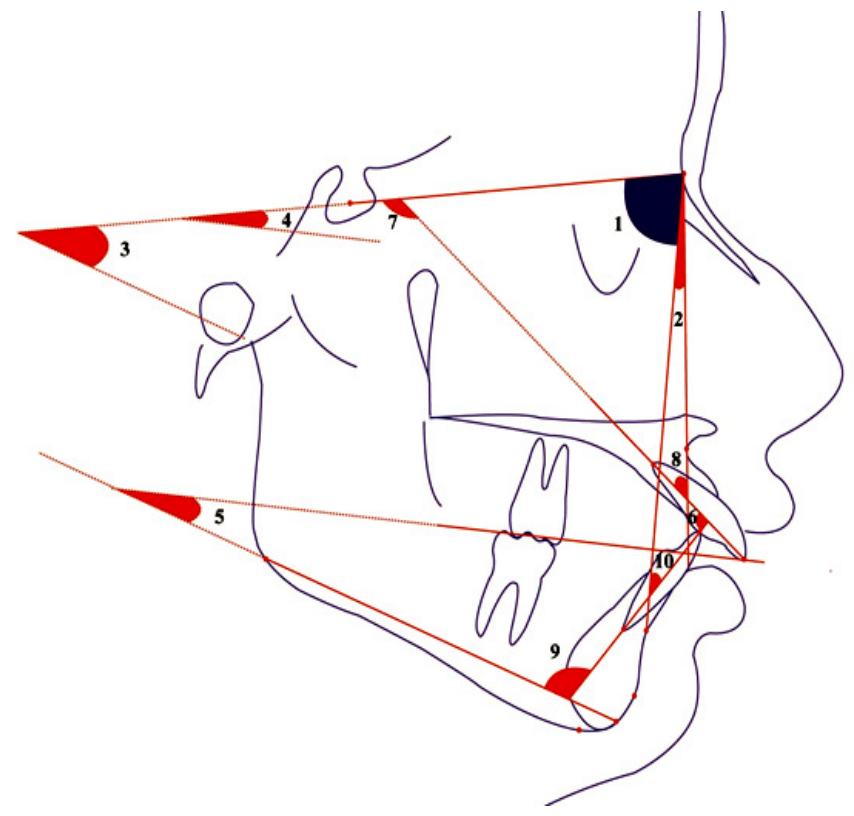

Fig (1) Angular measurements: $\operatorname{SNA}(1+2), \operatorname{SNB}(1), \operatorname{ANB}(2), \operatorname{SN} / \mathrm{MP}(3), \mathrm{SN} / \mathrm{OP}(4)$, OP/MP(5), U1/L1(6), U1/SN(7),U1/NA(8), L1/MP(9), L1/NB(10). 


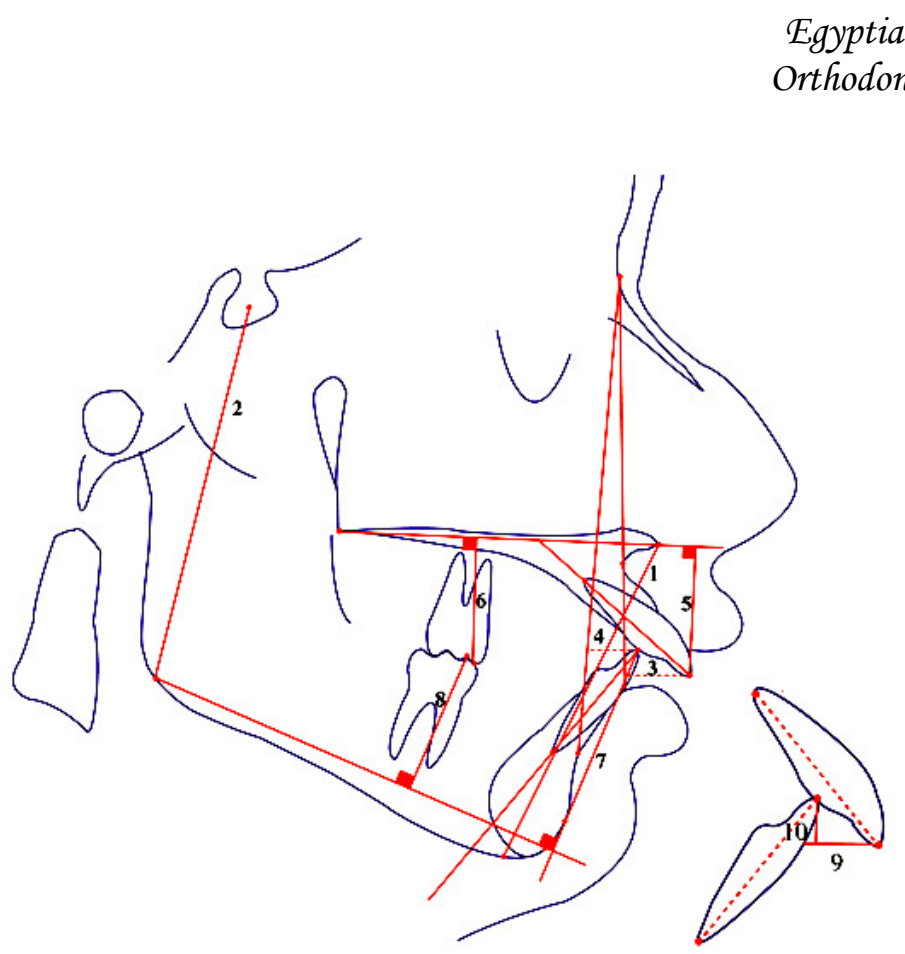

Fig (2) Linear measurements: ANS-Me(1), S-Go(2), U1-NA(3), U1-NB(4), U1-PP(5), U6-PP(6), L1-MP(7), L6-MP(8), Over jet(9), Overbite(10).

\section{RESULTS}

Treatment changes in class II division 1 and 2 groups and the significant of changes presented in Tables (1:3) and Figures (3:11).

\section{Angular measurements (Table 1)}

The mean of $\mathrm{SNA}^{0}$ decreased significantly $(\mathrm{P}<0.05)$ in both group, while $\mathrm{SNB}^{0}$ was not statistically significant different from $\mathrm{T} 1$ to $\mathrm{T} 2$ $(\mathrm{P}>0.05)$. The $\mathrm{ANB}^{0}$ demonstrated significant decrease in class II division 2, while in class II division1 the decrease didn't reach the significant level of difference $(\mathrm{P}>$.0.05.)

Class II division 1 cases showed significant decrease in $\mathrm{SN} / \mathrm{MP}^{0}$, while class II division 2 showed significant increase from T1-T2 which represent anti- clockwise and clockwise rotation of the mandible respectively. 
There was significant decrease in $\mathrm{SN} / \mathrm{OP}^{0}$ in both groups, and a significant increase in $\mathrm{OP} / \mathrm{MP}^{0}$ in class II division 2, while the difference in class II division1 was insignificant $(\mathrm{P}>0.05)$.

Reverse changes were obtained from T1-T2 regarding the incisor relationship and their inclination. The $\mathrm{U} 1 / \mathrm{L}^{0}{ }^{0}$ increased significantly with treatment in class II division 1 ; in contrast, it decreased with significant differences in class II division 2. The $\mathrm{U} 1 / \mathrm{SN}^{0}, \mathrm{U}_{1} / \mathrm{NA}^{0}, \mathrm{~L} 1 / \mathrm{MP}^{0}, \mathrm{~L} 1 / \mathrm{NB}^{0}$ decreased significantly in class II division 1, on the other hand they were increased significantly in class II division 2 from T1-T2.

\section{Linear measurements (Table 2)}

Both groups exhibited significant increase of the posterior face height (S-Go). The lower anterior face height (ANS-Me) noted an increase from T1-T2 with significant difference in class II division 2, without reaching the significant level in class II division 1 cases.

The linear measurements which displayed the changes in incisor inclination (U1-NA, L1-NB), in addition to the over jet, showed significant differences from T1-T2 in both groups, with reverse changes.

Both groups displayed significant increase in the vertical position of the maxillary and mandibular molars (U6-PP, L6-MP), indicating their extrusion.

The vertical relation of upper incisor (U1-PP) in class II division 1 and lower incisors (L1-MP) in class II division 2 showed insignificant changes $(\mathrm{P}>0.05)$. On the other hand, U1-PP in class II division 2 and L1-MP in class II division 1 showed significant decrease $(\mathrm{P}<0.05)$ concurrent with treatment and overbite correction.

Table (3) and Fig (3) revealed that class II division 1 cases had a deeper overbite at $\mathrm{T} 1$, while at $\mathrm{T} 2$ both groups showed nearly similar results of bite depth $(2.7,2.6 \mathrm{~mm})$. Changes of overbite as a result of treatment, within each group and between them, showed significant differences. 


\section{Egyptian \\ Orthodontic Journal}

Table (1): Comparison of mean values of angular measurements before and after treatment

\begin{tabular}{|c|c|c|c|c|c|c|c|c|}
\hline \multirow{2}{*}{$\begin{array}{l}\text { Angular } \\
\text { measures }\end{array}$} & \multicolumn{4}{|c|}{ Class II-1 Mean \pm SD } & \multicolumn{4}{|c|}{ Class II-2 Mean \pm SD } \\
\hline & T1 & $\mathbf{T 2}$ & T1-T2 & p & T1 & $\mathbf{T 2}$ & T1-T2 & p \\
\hline SNA & $80.4 \pm 4.0$ & $78.8+4.2$ & $-1.6 \pm 0.8$ & $0.002 *$ & $82.5 \pm 3.3$ & $80.1+3.0$ & $-2.4 \pm 0.5$ & $0.005^{*}$ \\
\hline SNB & $75.1 \pm 2.9$ & $74.8+3.9$ & $-0.3+3.5$ & 0.858 & $77.4+3.3$ & $77.5 \pm 2.9$ & $0.1 \pm 0.7$ & 0.438 \\
\hline ANB & $5.3 \pm 1.6$ & $4.0 \pm 4.3$ & $-1.3 \pm 2.9$ & 0.195 & $5.1 \pm 0.57$ & $2.55 \pm 0.64$ & $-2.5 \pm 0.8$ & $0.005^{*}$ \\
\hline SN/MP & $33.9+1.5$ & $32.4+1.4$ & $-1.5+1.1$ & $0.005^{*}$ & $28.4+1.3$ & $31.0+1.3$ & $2.5 \pm 0.5$ & 0.004* \\
\hline SN/OP & $22.0 \pm 3.9$ & $19.8+4.3$ & $-2.2 \pm 0.5$ & $0.002 *$ & $15.5 \pm 1.1$ & $13.9 \pm 0.7$ & $-1.5 \pm 0.7$ & 0.004* \\
\hline OP/MP & $15.2+2.3$ & $15.7 \pm 1.1$ & $0.5 \pm 2.6$ & 0.341 & $11.3+0.9$ & $13.2+1.0$ & $1.8 \pm+0.5$ & 0.004* \\
\hline U1/L1 & $105.5 \pm 7.4$ & $126.7 \pm 2.0$ & $21.2 \pm 6.7$ & $0.002 *$ & $151.8 \pm 1.9$ & $128.2 \pm 2.0$ & $-23.5 \pm 3.0$ & $0.005^{*}$ \\
\hline U1/SN & $116.7 \pm 7.8$ & $100.3 \pm 2.6$ & $-16.3+7.9$ & $0.002 *$ & $88.3+1.6$ & $98.7 \pm 3.2$ & $10.3+3.0$ & $0.005^{*}$ \\
\hline U1/NA & $36.4+5.4$ & $24.2+3.8$ & $-12.2+5.4$ & $0.002 *$ & $4.2+1.0$ & $23.0 \pm 2.5$ & $18.8+2.8$ & $0.005^{*}$ \\
\hline L1/MP & $103.7 \pm 2.7$ & $97.0 \pm 1.3$ & $-6.7 \pm 2.7$ & $0.002 *$ & $95.0 \pm 1.6$ & $101.9 \pm 2.8$ & $6.9 \pm 1.8$ & $0.005^{*}$ \\
\hline L1/NB & $32.6+4.1$ & $29.7 \pm 4.1$ & $-2.9+3.9$ & $0.040 *$ & $22.3+1.0$ & $29.2+1.2$ & $6.9 \pm 1.3$ & $0.005^{*}$ \\
\hline
\end{tabular}

*Significant at $\mathrm{P}<0.05$ (black).

Table (2): Comparison of mean values of linear measurements before and after treatment

\begin{tabular}{|l|c|c|c|c|c|c|c|c|}
\hline \multirow{2}{*}{$\begin{array}{l}\text { linear } \\
\text { measures }\end{array}$} & \multicolumn{4}{|c|}{ Class II-1 Mean \pm SD } & \multicolumn{3}{c|}{ Class II-2 Mean \pm SD } \\
\cline { 2 - 9 } & T1 & T2 & T1-T2 & p & T1 & T2 & T1-T2 & P \\
\hline ANS-Me & $68.1 \pm 5.0$ & $69.4 \pm 6.6$ & $1.3 \pm 2.1$ & 0.057 & $61.8 \pm 1.2$ & $64.0 \pm 0.9$ & $2.2 \pm 0.6$ & $\mathbf{0 . 0 0 5 *}$ \\
\hline S-Go & $75.2 \pm 5.6$ & $77.3 \pm 7.1$ & $2.1 \pm 1.7$ & $\mathbf{0 . 0 0 5 *}$ & $71.5 \pm 1.2$ & $73.3 \pm 1.3$ & $1.8 \pm 0.6$ & $\mathbf{0 . 0 0 5 *}$ \\
\hline U1-NA & $8.9 \pm 1.5$ & $5.2 \pm 1.0$ & $-3.7 \pm 1.3$ & $\mathbf{0 . 0 0 2} *$ & $1.9 \pm 0.6$ & $4.9 \pm 0.7$ & $2.9 \pm 0.7$ & $\mathbf{0 . 0 0 5 *}$ \\
\hline L1-NB & $9.4 \pm 1.1$ & $7.6 \pm 0.9$ & $-1.8 \pm 1.1$ & $\mathbf{0 . 0 0 2} *$ & $2.6 \pm 0.8$ & $4.8 \pm 0.9$ & $2.1 \pm 0.7$ & $\mathbf{0 . 0 0 5 *}$ \\
\hline U1-PP & $30.4 \pm 4.2$ & $29.0 \pm 3.5$ & $-1.4 \pm 5.7$ & 0.422 & $27.6 \pm 1.5$ & $25.5 \pm 1.6$ & $-2.1 \pm 0.7$ & $\mathbf{0 . 0 0 5 *}$ \\
\hline U6-PP & $22.5 \pm 1.8$ & $24.7 \pm 2.7$ & $2.2 \pm 1.5$ & $\mathbf{0 . 0 0 4} *$ & $20.3 \pm 1.0$ & $22.0 \pm 1.0$ & $1.7 \pm 0.3$ & $\mathbf{0 . 0 0 4 *}$ \\
\hline L1-MP & $41.4 \pm 3.9$ & $37.6 \pm 4.0$ & $-3.8 \pm 2.5$ & $\mathbf{0 . 0 0 2} *$ & $36.1 \pm 1.7$ & $36.0 \pm 1.8$ & $-0.1 \pm 0.6$ & 0.454 \\
\hline L6-MP & $29.2 \pm 2.9$ & $31.9 \pm 4.1$ & $2.7 \pm 2.7$ & $\mathbf{0 . 0 0 7 *}$ & $27.4 \pm 1.4$ & $29.3 \pm 1.6$ & $1.9 \pm 0.5$ & $\mathbf{0 . 0 0 4 *}$ \\
\hline Overjet & $8.3 \pm 1.7$ & $2.7 \pm 0.4$ & $-5.6 \pm 1.7$ & $\mathbf{0 . 0 0 2 *}$ & $1.6 \pm 0.6$ & $2.6 \pm 0.5$ & $1.0 \pm 0.6$ & $\mathbf{0 . 0 1 0 *}$ \\
\hline Overbite & $6.7 \pm 0.7$ & $2.7 \pm 0.4$ & $-4.0 \pm 1.1$ & $\mathbf{0 . 0 0 2 *}$ & $5.5 \pm 0.5$ & $2.9 \pm 0.5$ & $-2.6 \pm 0.6$ & $\mathbf{0 . 0 0 5 *}$ \\
\hline
\end{tabular}

*Significant at $\mathrm{P}<0.05$.

Table (3) Comparison of mean values of overbite between groups

\begin{tabular}{|l|c|c|c|}
\hline 0verbite & $\begin{array}{c}\text { Mean } \pm \text { SD } \\
\text { Class II-1 }\end{array}$ & $\begin{array}{c}\text { Mean } \pm \text { SD } \\
\text { Class II-2 }\end{array}$ & P Value \\
\hline T1 & $6.7 \pm 0.7$ & $5.5 \pm 0.5$ & $0.010^{*}$ \\
\hline T2 & $2.7 \pm 0.4$ & $2.9 \pm 0.5$ & 0.195 \\
\hline T1-T2 & $-4.0 \pm 1.1$ & $-2.6 \pm 0.6$ & $0.002 *$ \\
\hline
\end{tabular}

*Significant at $\mathrm{P}<0.05$. 


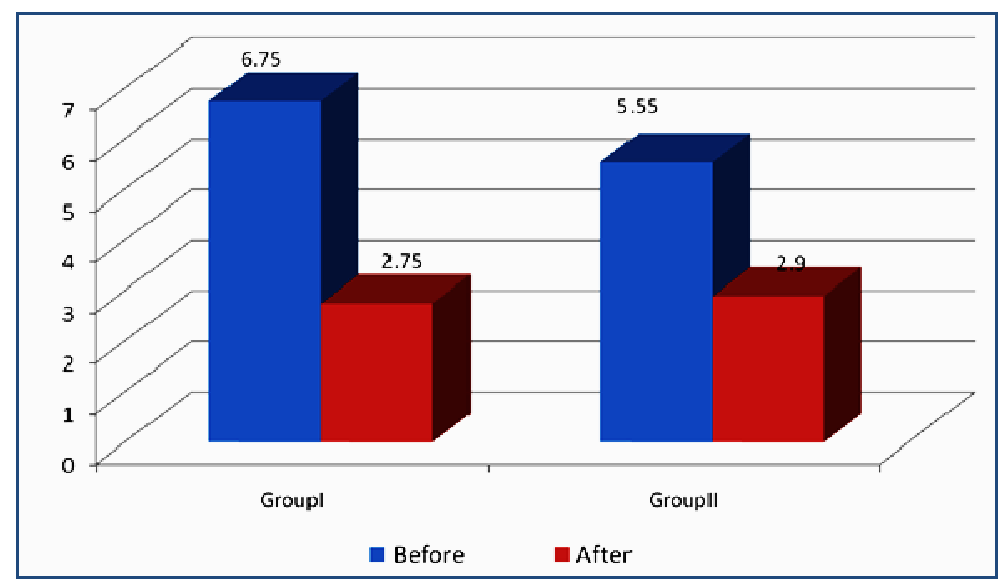

Fig (3): Comparison of mean values of overbite before and after treatment between the studied groups.

Changes obtained concurrent with treatment could be observed from anterior and lateral photographs (Fig 4,6) and pre and post treatment lateral cephalometric films of the cases (Fig 5,7). Tracing of T1 and T2 for class II division 1 and 2 were superimposed and traced on SN line at $\mathrm{S}$ point (Fig 8,10) and on the fixed maxillary and mandibular structures (Fig 9,11) to present the angular and linear changes.
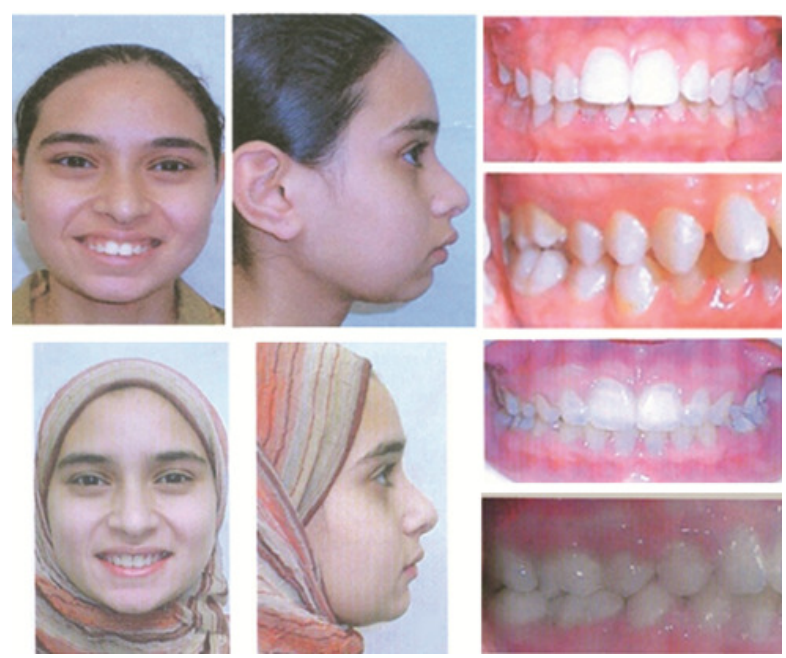

Fig (4): Pre and post treatment anterior and lateral photographs of class II division 1 case. 


\section{Egyptian}

Orthodontic Journal
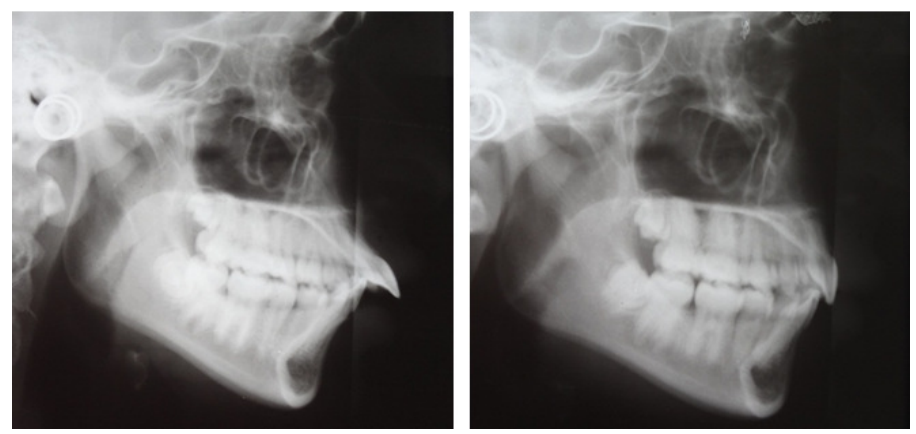

Fig (5): Pre and post treatment lateral cephalometric x-ray films of the same patient with class II division 1.
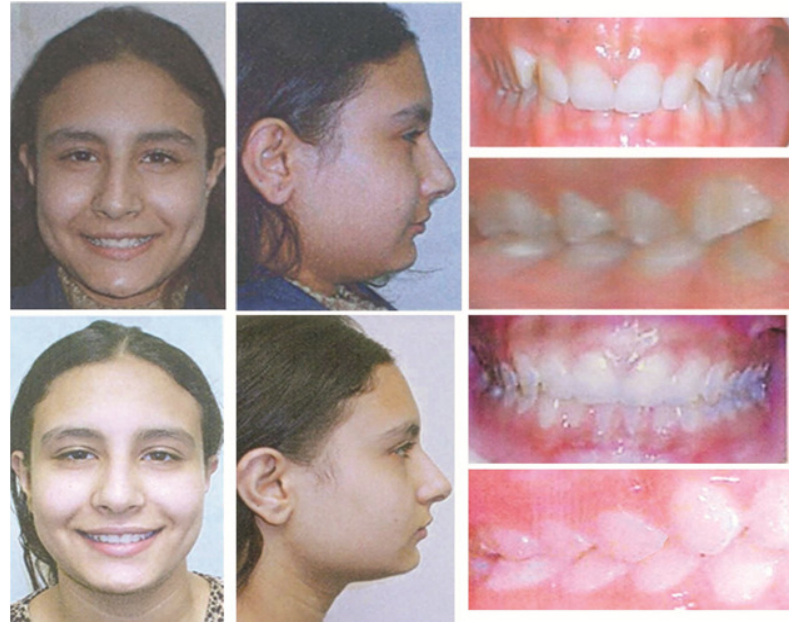

Fig (6): Pre and post treatment anterior and lateral photographs of class II division 2 case.
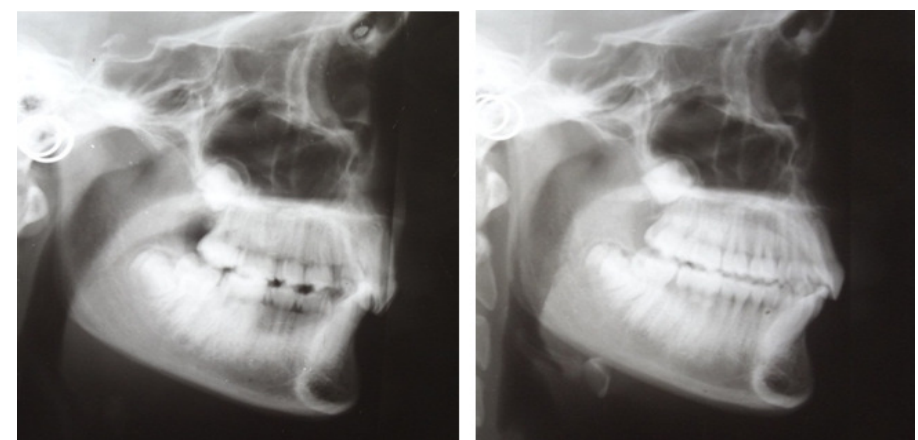

Fig (7): Pre and post treatment lateral Cephalometric x-ray films (the same patient) with class II division 2 .

Volume 41 - June 2012 


\section{Egyptian}

Orthodontic Journal

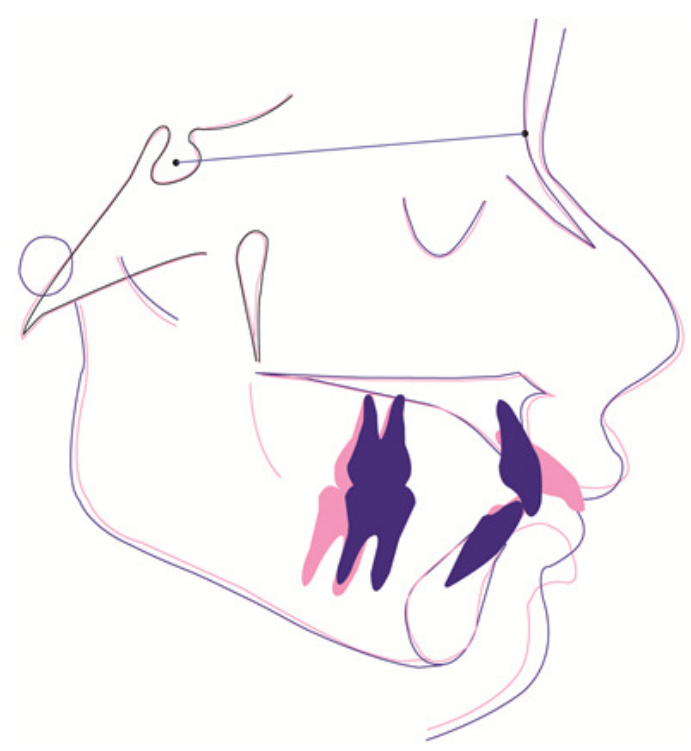

Fig (8): Class II division 1 case: T1 (pink) and T2 (blue) cephalometric tracings superimposed on S-N at Sella.

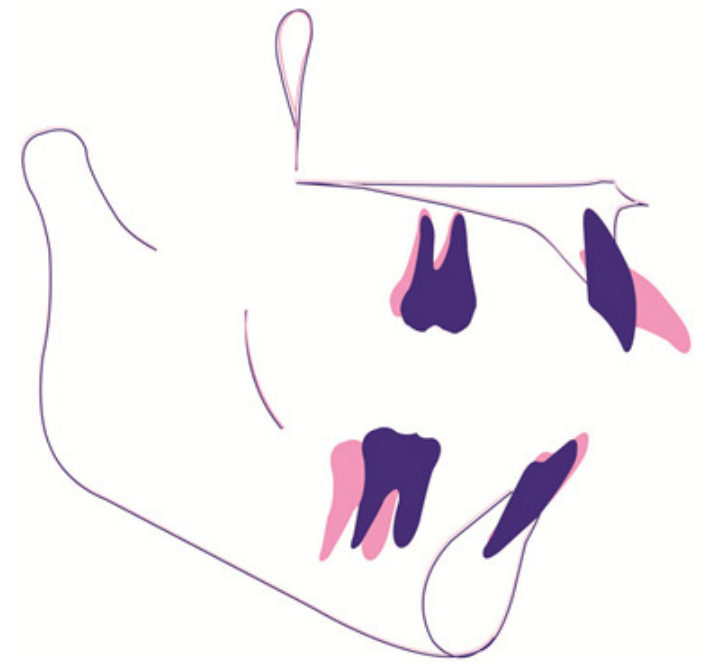

Fig (9): The maxillary and mandibular regional superimpositions on the stable structures show the dentoalveolar changes in the molar and incisor areas. Note the changes between $\mathrm{T} 1$ and $\mathrm{T} 2$; maxillary incisor retroclination, maxillary and mandibular molars extrusion and lower incisor intrusion. 


\section{Egyptian}

Orthodontic Journal

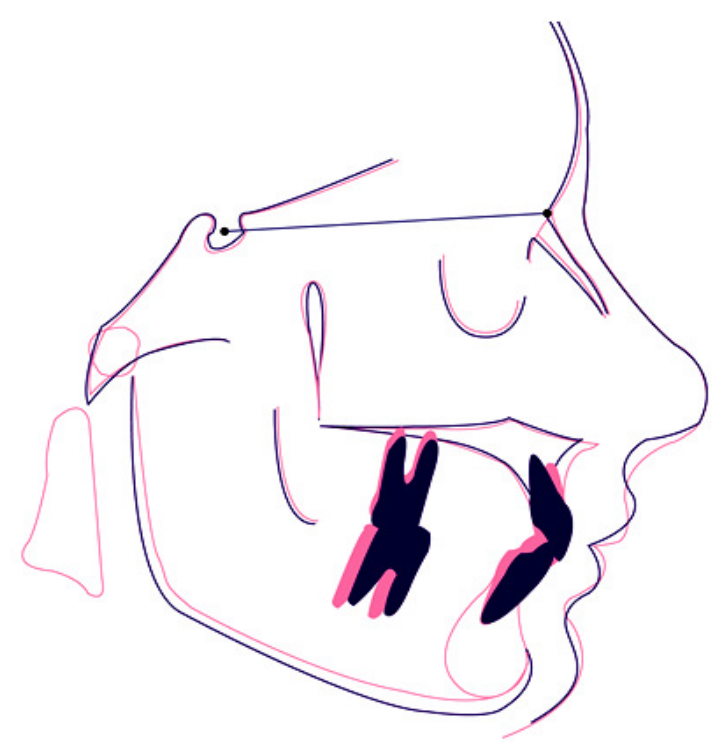

Fig (10): Class II division 2 case: $\mathrm{T} 1$ (pink) and $\mathrm{T} 2$ (blue) cephalometric tracings superimposed on S-N at Sella.

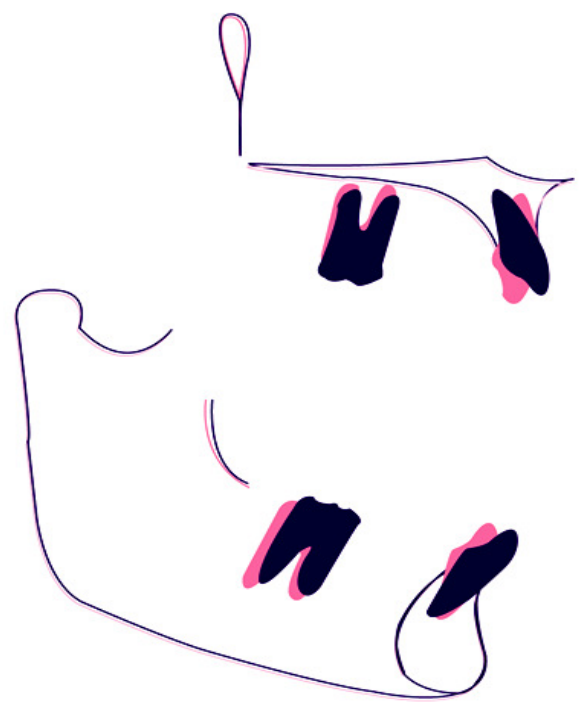

Fig (11): The maxillary and mandibular regional superimpositions on the stable structures show the dentoalveolar changes in the molar and incisor areas. Note the changes between T1 and T2; maxillary incisor proclination and intrusion, maxillary and mandibular molars extrusion and lower incisor proclination. 
Egyptian

Orthodontic Journal

\section{DISCUSSION}

The orthodontic profession has assumed much of the responsibility for the improvement in function of the teeth and jaws. Since function is closely associated with overbite, the correction of vertical overbite discrepancies comprises a major part of clinical orthodontics. This investigation was undertaken to evaluate the dento-skeletal changes produced by a fixed appliance for the correction of excessive overbites in class II cases. The changes with treatment were described without reference to the mechanics used, as Paker et $\mathrm{al}^{23}$ and, Noroozi, et $\mathrm{al}^{24}$ found that variation of some of the changes existed but they were not statistically significant, as the use of different treatment mechanics aimed to obtain treatment objectives mainly intrusion of incisors and extrusion of molars.

All the measurements showed changes that were statistically significant with overbite correction except $\mathrm{SNB}^{0}$ in both groups, and $\mathrm{ANB}^{0}, \mathrm{OP} / \mathrm{MP}^{0}, \mathrm{U} 1-\mathrm{PP}, \mathrm{ANS}-\mathrm{Me}$ in group 1, and L1-MP in group 2. The class II correction was obtained in all deepbite treated cases as evidenced by the improvement of the maxillomandibular relationship $\left(\mathrm{ANB}^{0}\right)$, in spite of insignificant differences of the change in class II division 1. This improvement resulted from reduction of $\mathrm{SNA}^{0}$ from T1-T2 with significant differences, and considered as a dental change because the position of incisor roots influences the position of point A. Mitchell and Kinder ${ }^{25}$ demonstrated that point $A$ can be repositioned 2 $\mathrm{mm}$ posteriorly when the upper incisor roots are moved towards the palate, which occurred concurrent with deepbite correction. Consequently more improvement was observed in group 2 which had more up righted incisors. These results were in accordance with that obtained by previous studies ${ }^{23,26,27}$.

A significant increase in the intermaxillary divergence $\mathrm{SN} / \mathrm{MP}^{0}$, $\mathrm{OP} / \mathrm{MP}^{0}$ were found in class II division 2 group which represent clockwise rotation of the mandible and anticlockwise rotation of occlusal plane. The findings of the current study are comparable to those reported in the longitudinal clinical trial by Schütz-Fransson and colleagues ${ }^{28}$, who adopted overbite correction associated with bite opening of the intermaxillary divergence. These results seem to recommend a more 
Egyptian

Orthodontic Journal

aggressive therapeutic approach to deepbite in growing subjects facilitated by possibly adding biomechanical details aimed specifically at further improving the vertical occlusal relationships during treatment with fixed appliances ${ }^{29,30}$.

In class II division $1 \mathrm{SN} / \mathrm{MP}^{0}$ was decreased significantly from T1-T2 $\left(-1.5^{0}\right)$. As this group have more hyper divergent angle $\left(33.9^{0}\right)$ than the class II division 2 group $\left(28.45^{\circ}\right)$, it is advisable to prevent bite opening effects that could result in a downward and backward mandibular rotation which exacerbate the malocclusion ${ }^{31}$. Also during treatment of extraction cases, molars had a tendency to come forward and anchorage slipped more when the premolars were removed, which results in decreasing of $\mathrm{SN} / \mathrm{MP}^{0}$ from T1-T2, which is preferable for retention after treatment of overbite ${ }^{23}$. It was found that the greater the inclination of mandibular plane before treatment, the more favorable the outcome of treatment in terms of overbite reduction approximately 1 year after the end of therapy. Better outcomes can be expected in subjects showing normal or high-angle rather than low-angle intermaxillary vertical relationships $^{32,33}$.

There were significant reductions of $\mathrm{SN} / \mathrm{OP}^{0}$ in both groups, whereas $\mathrm{OP} / \mathrm{MP}^{0}$ was significantly reduced in group 2 . However, the post treatments change in group 1was insignificant. The findings of the current study were comparable to those reported by Bernstein et $\mathrm{al}^{27}$. The correlation between bite depth and inclination of occlusal plane was recorded early bySchudy ${ }^{34} \mathrm{Tovstein}^{35}$. The increase of OP/MP ${ }^{0}$ from $\mathrm{T} 1$ to $\mathrm{T} 2$ probably resulted from repositioning the maxillary occlusal plane downward posteriorly concurrent with molar extrusion and incisor intrusion.

In the present investigation, the angular (SN/U1, U1/NA, L1/MP, L1/NB, U1/L1) and linear (U1-NA, L1-NB, overjet) measurements were used to evaluate the incisors position. Changes in class II division 1 group showed a reverse pattern of changes in class II division 2 from T1 to T2 concurrent with deep bite correction. Depending on the original inclination, flaring of incisors can be desirable (class II division 2), undesirable, or even contraindication, as in class II division I malocclusion ${ }^{36}$. So significant increase of these angular and dental measurements was 
Egyptian

Orthodontic Journal

obtained and therefore resulted in more procumbent incisors in class II division 2 cases, which found to be clinically acceptable and stable in the long term with deep bite correction ${ }^{27}$. On the other hand, lingual inclination was observed in class II division 1 cases with significant decrease of the same measurements ${ }^{37}$.

This result was in agreement with Parker et $\mathrm{al}^{23}$ and Eberhart et $\mathrm{al}^{38}$. They found that the change of incisor inclination has a distinct effect on overbite.

The Overjet displayed significant improvements from T1-T2 with deep bite correction simultaneous to changes of axial inclination of anterior teeth.

The interincisal angle is a reflection of upper and lower incisor inclination. When a deep overbite develops, accompanied by a wide interincisal angle, it tends to force the crowns of the mandibular incisors lingually and the apices of the maxillary incisors labially ${ }^{35}$. This, in turn, increases the interincisal angle, which causes more overbite; thus a symbiotic relationship develops between the size of the interincisal angle and the depth of the overbite. Engel et al ${ }^{39}$ suggested an interincisal angle between $125^{\circ}$ and $135^{\circ}$ at the end of treatment for stability. In the present study, the average of interincisal angle was $126^{0} .7 \pm 2.0$ in group I and $128^{0} .2 \pm 2$ in group 2. This angle decreased in the uprighted and retroclined incisors, class II division 2, and increased in in class II division1 which had more proclined angle, with significant differences concurrent with deep bite correction. These findings corroborate findings by Bjork ${ }^{40}$, Burzin and Nanda ${ }^{41}$, Kim and Little ${ }^{42}$ who reported that deep bite depends on the relation between the upper and lower incisors and was believed to play a critical role in overbite correction.

In a patient with a class II malocclusion when a portion of the extraction spaces is used to correct the molar relationship, the molars are protracted $^{43}$, yet this protraction does not necessarily produce a loss of vertical dimension. Most orthodontic mechanics are extrusive in nature, and this extrusion appears to maintain or even increase the vertical dimension ${ }^{44}$. In spite of extrusive orthodontic mechanics used to correct the deep overbite, lower anterior face height (ANS-Me) in group 1 did 
Egyptian

Orthodontic Journal

not revealed a significant change in the present sample with deep bite correction. Protraction of molars may neutralize these effects. Meanwhile, cases in class II division 2 showed significant increase in the lower anterior face height from T1-T2 accompanied with molar extrusion. In this group mandible was forced to a slight posterior rotation, which in turn led to increase vertical facial heights.

A significant increase was also found in the posterior facial height (S-Go) in both groups. This finding was similar to the results of McDowell\& Baker ${ }^{45}$ and Pakers et $\mathrm{al}^{23}$. Weiland et $\mathrm{al}^{36}$ had conflicting results with the present study. It was possibly due to the older age of the patients (18-40 years), additionally, in his study anchorage mechanics were used to prevent extrusion of the molars and to control the vertical facial heights.

Regarding the linear measurement of U1-PP, both groups exhibited a decrease from T1-T2, which was significant only in class II division 2 cases. Class II division 1 group showed a decrease of $-1.4 \mathrm{~mm}$, and the class II division 2 sample showed a decrease of $-2.1 \mathrm{~mm}$. This change in distance considered the amount of intrusion of the maxillary incisor. However, some of the changes in this distance could also be attributed to incisor proclination depending on pretreatment angulation of the teeth ${ }^{23}$.

Assessment of the degree of lower incisor intrusion, as revealed by measure L1-MP, showed $-0.1 \mathrm{~mm}$ of intrusion in class II division 2, which was not statistically significant $(\mathrm{P}>0.05)$. This result was in accordance with previous results ${ }^{42,34}$, which found that incisor intrusion should be avoided during treatment of class II division 2 cases.

Lower incisor in class II division 1 demonstrated intrusion with significant differences, as L1-MP reduced by $-3.8 \mathrm{~mm}$ from T1- T2. This result was in accordance with that obtained by Samuelson et $\mathrm{al}^{46}$ and Hellekant et $\mathrm{al}^{47}$ as they suggested that in class II division 1 cases the tooth movements most commonly seen in treatment to reduce excessive overbite occur mainly in the mandibular arch, the change was significantly correlated to the reduction in vertical height of the mandibular incisor and to the changes in the angulation of the mandibular incisor to the mandibular plane. 
Cases with deep overbite had underdeveloped upper and lower molar heights due to absence of a stable incisal occlusion, which could affect not only the mandibular rotation, but also the dentoalveolar development ${ }^{48}$. In such cases a differentiated eruption of incisors and molars failed to take place, and it was recommended to increase the value of molar heights with treatment. In the present study both groups showed significance extrusion of upper and lower molars as indicated by significant increase in the linear measurements of U6-PP and L6-MP. These results were consistent with the results of Parker et $\mathrm{al}^{23}$, Amasyalim et $\mathrm{al}^{49}$, Bernstein et $\mathrm{al}^{27}$, Qamar andRiaz ${ }^{50}$ Cvvrand Baratmen $^{51}$ and opposed to Weiland et $\mathrm{al}^{36}$.

It is not worthy that overbite was significantly reduced in both treated groups. Table (3) and Figure (1) revealed that overbite at T2 in the first group $(2.7 \mathrm{~mm})$ not significantly different $(\mathrm{P}>0.05)$ than that obtained in the group $2(2.9 \mathrm{~mm})$. This was in accordance with Kim \&little ${ }^{42}$, and opposite to the results of Simon\&Joondeph ${ }^{52}$, who stated that, on average, patients with a deep initial overbite also had a deeper final overbite. The difference in the results may be due to the sample size that did not contain a sufficient number of cases.

In the present study the overbite decreased significantly in both groups and the decrease was more than the amount of intrusion of the anterior teeth. So it could be concluded that not only the intrusion of the anterior teeth but also changes in their axial inclination and extrusion of molars were effective in the treatment of deep overbite.

\section{CONCLUSION}

Based on the present results, it can be concluded that bite depth improved an average of -5.6 in class II division 1, and -2.6 in class II division 2 with significant differences between the groups due to the following effects:

- Changes in the axial inclination of incisor teeth that were decreased in class II division 1, and increased in class II division 2.

- Intrusion of lower incisors, by decreasing their vertical relation to the mandibular plane in class II division 1, and intrusion of maxillary incisors in class II division 2 , by decreasing their vertical relation to the palatal plane. 
- Extrusion of upper and lower molars in both groups, by increasing their vertical relations to the palatal and mandibular planes respectively.

\section{REFERENCES}

1. Karlsen AT. Craniofacial characteristics in children with Angle Class II division 2 malocclusion with and without deepbite. Angle Orthod. 1994; 64:123-130.

2. Karlsen AT. Craniofacial characteristics in children with Angle classII-1malocclusion with and without deepbite. Angle Orthod. 1994; 64: 437-446.

3. Kim TW, Little RM. Postretention assessment of deep overbite correction in class II Division 2 malocclusion. Angle Orthod. 1999 ;69:175-86.

4. Hammond AB 3rd. Treatment of a class II malocclusion with deep overbite. Am J Orthod Dentofacial Orthop. 2002 ;121:531-537.

5. Van Steenbergen E, Burstone CJ, Prahl-Andersen B, Aartman IH. The role of a high pull headgear in counteracting side effects from intrusion of the maxillary anterior segment. Angle Orthod. 2004; $74: 480-6$.

6. Hans MG, Kishiyama C, Parker SH, Wolf GR, Noachtar R. Cephalometric evaluation of two treatment strategies for deep overbite correction. Angle Orthod. 1994; 64:265-274.

7. Marques LS, Armond MC, Ramos-Jorge ML, Vieira de Andrade RG, Bolognese AM . Correlations between dentoskeletal variables and deep bite in Class II Division 1 Individuals. Braz Oral Res. 2011; 1:56-62

8. Poulton DR. Correction of extreme deep overbite with orthodontics and orthognathic surgery. Am J Orthod Dentofacial Orthop.1989 96:275-280.

9. Bell WH, Jacobs JD, Legan H. Treatment of class II deep bite by orthodontic and surgical means. Am J Orthod.1984; 85:1-20.

10. Hug HU. Periodontal status and its relationship to variations in tooth position. An analysis of the findings reported in the literature. HelvOdontolActa. 1982; 26:11-24. 
11. Begg PR, Kesling PC. Begg orthodontic theory and technique. Philadelphia: WB Saunders; 1977.

12. Begg PR, Kesling PC. The differential force method of orthodontic treatment. Am J Orthod. 1977;71:1-39.

13. Ricketts RM. Bioprogressive therapy as an answer to orthodontic needs: Part II. Am J Orthod.1976; 70:359-397.

14. Hellsing E, Eliassons S. Effect of fixed anterior bite plane therapy a radiographic study. Am J Orthod Dentofacial Orthop. 1996; 110:61- 68.

15. Shroff B, Yoon WM, Lindauer SJ, Burstone CJ. Simultaneous intrusion and retraction using a three-piece base arch. Angle Orthod. 1997; 67:455-461.

16. Barton KA. Overbite changes in the Begg and edgewise techniques. Am J Orthod. 1972; 62:48-55.

17. Gordon JB. Treatment of deep-bite cases. Am J Orthod. 1980; 77:1-13.

18. Greig DG. Bioprogressivetherapy. overbite reduction with the lower utility arch. Br J Orthod. 1983; 10:214-216.

19. Hamdan AM, Rock WP. The effect of archwire forces on incisor intrusion. Br J Orthod. 1995; 22:155-160.

20. Xu TM, Lin JX, Kui H, Huang JF. Bite-opening mechanics as applied in the Begg Technique. Br J Orthod. 1994; 21:189-195.

21. Nanda R, Marzban R, Kuhlberg A. The Connecticut Intrusion. J Clin Orthod. 1998; 32:708-715.

22. Aydogdu E, Ozsoy OP. Effect of mandibular incisor intrusion obtained using a conventional utility arch vs bone anchorage. Angle Orthod 2011; 81: 767-775.

23. Parker CD, Nanda RS, Currier GF. Skeletal and dental changes associated with the treatment of deep bite malocclusion. Am J Orthod Dentofacial Orthop.1995; 107:382-393.

24. Noroozi H, Moeinzad H. Extrusion-based leveling with segmented arch mechanics. Int J Adult Orthod Orthog. Surg. 2002; 17:47-49. 
25. Mitchell DL, Kinder FD. A comparison of 2 torquing techniques on the maxillary central incisors. Am J Orthod 1973; 63:407-414.

26. Bishara S E, Cummins D M, Zaher A. Treatment and posttreatment changes in patients with Class II division 1 malocclusion after extraction and nonextraction treatment. Am J of Orthod Dentofacial Orthoped. 1997; 111: 18-27.

27. Bernstein RL, Preston CB, and Lampassoc J. Leveling the curve of Spee with a continuous archwire technique: A long term cephalometric study. Am J Orthod Dentofacial Orthop 2007; 131:363-71.

28. Schütz-Fransson U, Bjerklin K and Lindsten R. Long-term follow-up of orthodontically treated deep bite patients. Eur J Orthod. 2006; 28:503-512.

29. Franchia L, Alvetrob L, Giuntinic V, Masuccid C, Defraiae Eand Baccettia T. Effectiveness of comprehensive fixed appliance treatment used with the Forsus Fatigue Resistant Device in Class II patients. Angle Orthod. 2011; 81:678-683.

30. FranchiaL, Baccettib T, Giuntinic V, Masuccic C, Vangelistic A and Defraiad E. Outcomes of two-phase orthodontic treatment of deepbite malocclusions. Angle Orthod. 2011; 81:945-952.

31. Collins MK. A nonsurgical approach to treatment of a high angle class II, division 1 malocclusion in a nongrowing patient. Am J Orthod Dentofac Orthop 1996; 110: 678-81.

32. Nanda SK. Patterns of vertical growth in face. Am J Orthod Dentofacial Orthop. 1988; 93:103-116.

33. Nanda SK. Growth patterns in subjects with long and short faces. Am J Orthod Dentofacial Orthop. 1990; 98:247-258.

34. Schudy FF. The control of vertical overbite in clinical orthodontics. Angle Orthod. 1968; 38:19-3.

35. Tovstein BC. Behavior of the occlusal plane and related structures in class II mal occlusion. Angle orthod. 1955; 25:189-198.

36. Weiland FJ, Bantleon HP, Droschl H. Evaluation of continuous arch and segmented arch leveling techniques in adult patients. A clinical study. Am J Orthod Dentofacial Orthop.1996; 110:647-652. 
37. Sood S. Treatment of classII division 1 malocclusion in non-growing patient. Virtual. J O. [ serial on line]. 2010 October.

38. Eberhart BB, Kuftenic MM, Baker IM,. The relationship between bite depth and incisor angular changes. Angle Orthod 1990; 60:55-8.

39. Engel G, Cornforth G, Damerell JM, Gordon J, Levy P, Mc Alpine J, Otto R, Walters R, Chaconas S. Treatment of deep-bite cases. Am J Orthod. 1980; 77:1-13, 1980.

40. Bjork A. Prediction of mandibular growth rotation. Am J Orthod. $1969 ; 55$ :585-99.

41. Burzin J, Nanda R. The stability of deep overbite correction.In: Nanda R, Burstone CJ, editors. Retention and stability in orthodontics. 1th ed. Philadelphia: Saunders; 1993. p. 61-80.

42. KimTW and Little RM. Postretention assessment of deepbite correction in classII dividion 2 mal occlusion Angle Orthod. 1999; 69:175-186.

43. Staggers JA. A comparison of results of second molar and first premolar extraction treatment. Am J Orthod and Dentofac Orthop.1990; 98: 430-436.

44. Demir A, Uysal T, Sari Z, Basciftci FA. Effects of camouflage treatment on dentofacial structures in class II division 1 mandibular retrognathic patients. European Journal of Orthodontics. 2005; 27: 524-531.

45. McDowell EH, Baker IM. The skeleton dental adaptations in deep bite correction. Am J Orthod Dentofacial Orthop. 1991; 100:370-37 .

46. Samuelson G, Garner LD, Potter R. Tooth movements associated with deep overbite correction in Class II division 1 malocclusions. Inter J Orthod. 1989; 27: 3-8.

47. Hellekant M, Lagerström L, Gleerup A. Overbite and overjet correction in a Class II, division 1 sample treated with Edgewise therapy. Eur J Ortod, 1989, 11:91-106.

48. Bjork A and Skieller V. Facial development and tooth eruption. An implant study at the age of puberty. Am J Orthod. 1972; 62:339-383. 
49. Amasyalim D, Saudid H, Lmez H, Akin E, KaracayA. Intrusive effects of the Connecticut Intrusion Arch and the Utility Intrusion Arch. Turk J Med Sci. 2005; 35:407-414.

50. Qamar CR, Riaz M. ClassII division 2 malocclusion; Cephalometric skeletal evaluation. Pakistan Oral and Dent. J. 2011; 31:367- 370.

51. CvvrS, Baratam S. Deep bite $-\mathrm{A}$ review. Annals and Essences of Dentistry.2009; 11: 8- 25 .

52. Simon ME. Joondeph DR. Changes in overbite: a ten-year post retention study. Am J Orthod 1973; 64: 349-367. 